\title{
Efficient Optical Phase modalation using A Semiconductor Optical Amplifier
}

\author{
Gliese, Ulrik Bo; Nielsen, Torben Nørskov; Mikkelsen, Benny; Stubkjær, K.E.
}

Published in:

Summer Topical Meetings on Spaceborne Photonics: Aerospace Applications of Lasers and Electro-Optics (LEOS )

Publication date:

1991

Document Version

Publisher's PDF, also known as Version of record

Link back to DTU Orbit

Citation (APA):

Gliese, U. B., Nielsen, T. N., Mikkelsen, B., \& Stubkjær, K. E. (1991). Efficient Optical Phase modalation using A Semiconductor Optical Amplifier. In Summer Topical Meetings on Spaceborne Photonics: Aerospace Applications of Lasers and Electro-Optics (LEOS ): Optical Millimeter-Wave Interactions: Measurements, Generation, Transmission and Control (pp. 14-15). IEEE.

\section{General rights}

Copyright and moral rights for the publications made accessible in the public portal are retained by the authors and/or other copyright owners and it is a condition of accessing publications that users recognise and abide by the legal requirements associated with these rights.

- Users may download and print one copy of any publication from the public portal for the purpose of private study or research.

- You may not further distribute the material or use it for any profit-making activity or commercial gain

- You may freely distribute the URL identifying the publication in the public portal 


\title{
Efficient Optical Phase Modulation Using a Semiconductor Optical Amplifier
}

\author{
U. Gliese, T.N. Nielsen, B. Mikkelsen and K.E. Stubkjaer \\ Center for Broadband Telecommunications \\ Electromagnetics Institute, Technical University of Denmark \\ Building 348, DK-2800 Lyngby, Denmark
}

Advanced modulation formats such as PSK and QPSK are of high interest in optical microwave links. To obtain these modulation formats, it is necessary to use external modulators. Unfortunately, most of the external modulators available have the drawbacks of insertion loss and high power consumption. This is a problem especially in spaceborne systems, e.g. optical beam forming networks [1]. Recently, various experiments have demonstrated the feasibility of using optical amplifiers as phase modulators in optical communication systems [2]-[4]. These phase modulators provide the advantages of gain and low modulation power requirements.

Measured values of the modulation power necessary to obtain the PSK phase shift of $\pi$ is depicted in Fig. 1 and the necessary power for obtaining the QPSK phase shift of $\frac{3 \pi}{2}$ is easily found by adding $3.5 \mathrm{~dB}$ to these values. The $3 \mathrm{~dB}$ bandwidth is given at the point where the required modulation power has increased by $3 \mathrm{~dB}$ and is found to be $600 \mathrm{MHz}$. This bandwidth is determined by the carrier lifetime and can be increased by using higher bias currents although current heating would prevent a bandwidth greater than $1 \mathrm{GHz}$. It should be noticed, however, that the modulator presented here has sufficient bandwidth since the bit rates under consideration for microwave transmission links are normally lower than $500 \mathrm{Mbit} / \mathrm{s}$. It is expected that the bandwidth of $600 \mathrm{MHz}$ will allow for PSK modulation speeds of up to approximately $900 \mathrm{Mbit} / \mathrm{s}$ and QPSK modulation speeds of approximately twice this bit rate. Non-linearities may, however, limit the QPSK modulation speed to $900-1500 \mathrm{Mbit} / \mathrm{s}$. The required modulation power was found to be as low as $5 \mathrm{dBm}$ which corresponds to a $\mathrm{V}_{\pi}$ of $1,1 \mathrm{~V}$. This is comparable to or better than what can be expected for Lithium Niobate modulators with the same bandwidth. Finally, it should be noted that the measurements were performed for an optical input power of $-7 \mathrm{dBm}$, a bias current of $70 \mathrm{~mA}$ and a fibre to fibre gain of $10 \mathrm{~dB}$, resulting in an optical output power of $3 \mathrm{dBm}$.

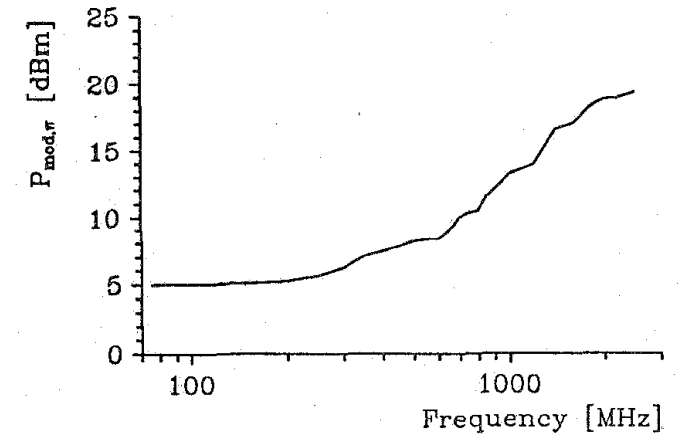

Figure 1: Required modulation power to obtain a phase shift of $\pi$ radians.

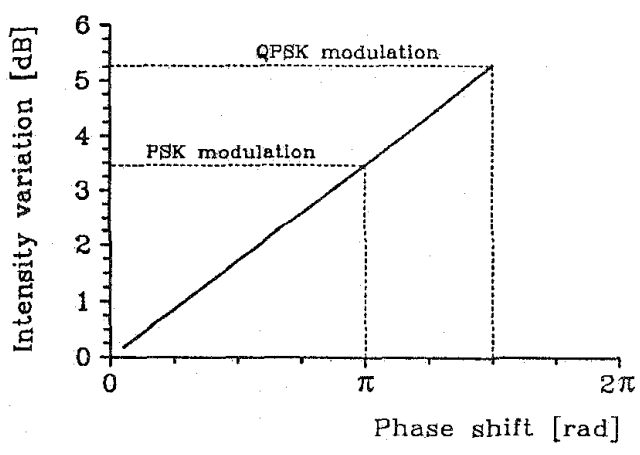

Figure 2: Intensity variation due to amplitude modulation versus the required phase shift. 
The major drawback of using the optical amplifier as a phase modulator is the inevitable amplitude modulation induced by the amplifier. As seen in Fig. 2, the intensity variation introduced by the amplitude modulation is rather large and for QPSK modulation variations of up to $5 \mathrm{~dB}$ can be expected. This is not tolerable in practical systems.

A novel method for reducing the amplitude modulation is the use of a two-electrode amplifier as illustrated in Fig. 3. It is possible to reduce the amplitude modulation by modulating the two electrodes in anti-phase. The modulation powers are adjusted so that the two sections will introduce the same amount of amplitude modulation. This will result in a cancellation of the amplitude modulation since the modulation is $\pi$ radians out of phase in the two sections. In order to avoid an associated reduction of the phase modulation, the phase response per $\mathrm{mA}$ of modulation current has to be different in the two sections. The ratio between the phase and amplitude modulation is governed by the so called linewidth enhancement factor $\alpha$ [5] which for a fixed wavelength increases with the electron concentration [5]. To obtain a good overall phase response, the electron concentration in the two sections of the amplifier must therefore be different. This is easily achieved by saturating the amplifier with a high power optical input signal (above $-10 \mathrm{dBm})$ and by lowering the bias current in the output section.

A multi-section numerical model has been used to calculate the intensity variation due to amplitude modulation in the two-electrode amplifier. The predicted intensity variation is shown in Fig. 4 as a function of the anti-phase modulation index, i.e. the ratio of the modulation current in the input section and the modulation current in the output section. It is seen that the intensity variation can be reduced from $3.5 \mathrm{~dB}$ to $0.8 \mathrm{~dB}$ ( $77 \%$ reduction) for the PSK modulation format.

The results show that the optical amplifier may be an attractive solution for phase modulation even in spaceborne systems. Furthermore, the semiconductor optical amplifiers have the great advantage of potential optoelectronic integration in future systems.

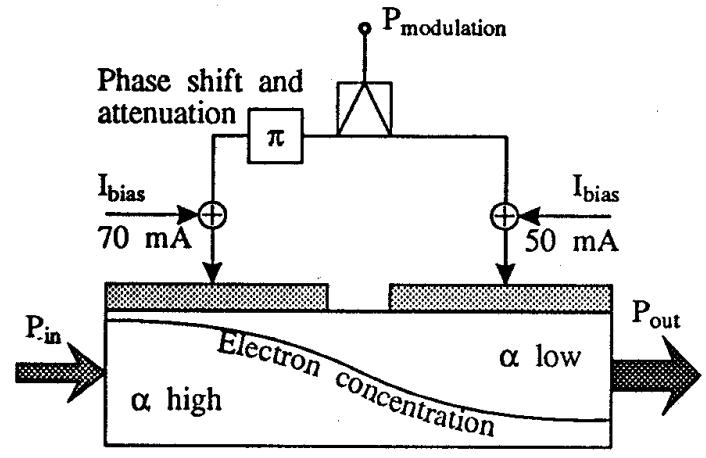

Figure 3: Two-electrode amplifier with antiphase modulation concept.

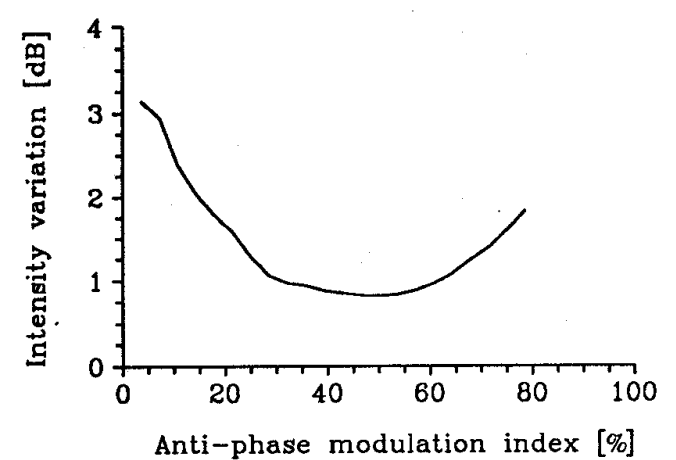

Figure 4: Intensity variation versus anti-phase modulation index for a phase shift of $\pi$ radians.

\section{References}

[1] U. Gliese et al.: In Proceedings of CLEO, 1991, paper CWM5.

[2] J. Mellis et al.: Electronics Letters, vol. 25, no. 10, pp. 679-682, 1989.

[3] G. Großkopf et al.: In Proceedings of IOOC, 1989, paper 21B4-2.

[4] D. Hui Bon Hoa et al.: Journal of Ligthwave Technology, vol. 9, no. 2, pp. 266-270, 1991.

[5] N. Storkfelt et al.: Submitted for publication in Photonics Technology Letters, 1991. 